\title{
Preparation and characterization of electrodeposited Ni-Ru alloys: morphological and catalytic study
}

\author{
Dawid Kutyła ${ }^{1}$ (D) Karolina Kołczyk-Siedlecka ${ }^{1} \cdot$ Anna Kwiecińska ${ }^{1} \cdot$ Katarzyna Skibińska $^{1} \cdot$ Remigiusz Kowalik $^{1}$. \\ Piotr Żabiński ${ }^{1}$
}

Received: 21 February 2019 /Revised: 22 August 2019 / Accepted: 23 August 2019/Published online: 15 October 2019

(C) The Author(s) 2019

\begin{abstract}
Nickel-ruthenium alloys with various compositions have been deposited by electrodeposition for the first time. Cyclic voltammetry and linear stripping voltammetry measurements show that codeposition of nickel with ruthenium is possible below the potential value of nickel reduction. High-quality alloys containing nickel and ruthenium can be plated at cathodic potentials ranging from -0.5 to $-1.0 \mathrm{~V}$ vs SCE. Deposited coatings were characterized by X-ray diffraction (XRD), scanning electron microscopy (SEM), and atomic force microscopy (AFM). The diffractograms obtained show that an increase of nickel concentration in alloy will lead to a change in the phase composition and formation of $\mathrm{NiRu}(100)$ and (101) phases which is observed to be 78 mas.\% Ni. SEM studies confirm the surface homogeneity and presence of small, regular grains. AFM observation allows the estimation of the real surface area of obtained alloys which increase with more negative electrodeposition potentials. Ni-Ru alloys were found to be highly electroactive in the water splitting process, which can be connected with the presence of the NiRu phase and a well-developed electroactive area.
\end{abstract}

Keywords Nickel $\cdot$ Ruthenium $\cdot$ Electrodeposition $\cdot$ Hydrogen evolution reaction

\section{Introduction}

Metallic nickel is of great interest for a broad range of catalytic and electrochemical applications. One of the oldest and best-described processes is the cathodic evolution of hydrogen from alkaline solutions, which is also implemented to high-scale industrial performance [1-3]. It should be noted that the Tafel slope for $\mathrm{H}_{2}$ evolution on $\mathrm{Ni}$ is around $120 \mathrm{mVdec}^{-1}$ [4] which is not the lowest one, but hot alkaline solutions which are commercially used are quite inert to bulk nickel electrodes. Catalytic activity improvement can be performed

Electronic supplementary material The online version of this article (https://doi.org/10.1007/s10008-019-04374-7) contains supplementary material, which is available to authorized users.

Dawid Kutyła

kutyla@agh.edu.pl

1 Faculty of Non-Ferrous Metals, AGH University of Science and Technology, al. A. Mickiewicza 30, Krakow, Poland by different types of operations like active surface area development [5-7] or the formation of an alloy by adding a small amount of another element [8-15]. NiRaney electrodes are an excellent example of a material with a chemically enlarged active area which can tune the Tafel slope significantly to $32 \mathrm{mVdec}^{-1}$ [16]. The most straightforward method to achieve enhancement in catalytic activity is the combination of two metals from both parts of the volcano curve, which is considered to be state of the art in theoretical investigations in the field of electrocatalysis [17-20]. Most of the scientific literature in this field has focused on the creation of molybdenum and tungsten alloys with elements located on the left side of a volcano curve, like Co [21-23], Fe [24-27], and $\mathrm{Ni}$ [28-30], where the catalytic improvements were connected with an increase of the electroactive surface area and the formation of nanoor amorphous phases, demonstrating a synergetic effect [31-33].

Despite the brilliant catalytic activity of Mo- and Wbased alloys, it should be underlined that the alkaline environment is very corrosive for these two elements. 
Mo and $\mathrm{W}$ phases can be easily leached from a metallic matrix, destroy the alloy structure, and diminish their electrochemical performance.

For a long time, electrocatalytic materials based on pure platinum [34] and palladium [35] were considered to be an active material in electrochemical processes, but commercially not interesting due to very high prices and limited occurrences. The situation changed when scientists realized that the corrosion resistance of commercially used electrodes can be improved by the addition of a small amount of these elements to cathode material, which also affects their catalytic activity. Nowadays, based on these investigations, noble metal alloys with other elements like $\mathrm{Co}[36,37]$ and $\mathrm{Ni}[38,39]$ have become one of the most popular research objectives in field of electrochemistry.

Synthesis of nickel-noble metals alloys are under investigation in many research institutions all over the world. In scientific literature, some examples of Ni-Ru catalytic materials for ammonia decomposition [40], hydrogen evolution from alkaline solutions [41], or steam reforming of npropanol [42] can be found.

Investigations connected with the hydrogen evolution process on $\mathrm{Ni}-\mathrm{Ru}$ materials obtained by electrodeposition are limited only to some work connected with the spontaneous deposition of $\mathrm{Ru}$ on a nickel surface [43]. Occurrences of $\mathrm{Ru}$ on Ni dramatically changed the mechanism of hydrogen evolution from the Tafel slope around 120 to $40 \mathrm{mVdec}^{-1}$ for Ruactivated Ni. This evidence is explained by the increase in the exposed surface area of $\mathrm{Ru}$ deposits and the presence of a highly active metallic layer. Sol-gel fabricated $\mathrm{Ru}_{1-x} \mathrm{Ni}_{x} \mathrm{O}_{2-y}$ electrodes are considered to be a very promising type of materials for oxygen evolution reaction in an alkaline environment, which can be tailored by crystalline structure on thermal treatment process [44]. The catalytic effect of the $\mathrm{Ni}$ and $\mathrm{Ru}$ combination with $\mathrm{Ti}$ and $\mathrm{Fe}$ additions to the metallic matrix has been investigated in some studies connected with chlorate electrolysis $[45,46]$.

To the best of our knowledge, there have been no reports on the electrochemical synthesis of nickel-ruthenium materials from aqueous solutions. As mentioned above, deposition of alloys with even small concentrations of noble metal can drastically improve the catalytic activity in alkaline environment and achieve very good corrosion resistance under operation conditions.

In this work, we studied the process of electrochemical codeposition of nickel with ruthenium from chloride solutions. Cyclic voltammetry measurement results show the possibility of fabricating thin $\mathrm{Ni}-\mathrm{Ru}$ films. Modification of the plating potential and concentration of ions in electrolytes varied the chemical and phase composition of deposits. After characterization measurements, $\mathrm{Ni}-\mathrm{Ru}$ coatings were used as a cathode for the water splitting process in an alkaline solution.

\section{Experimental}

\section{Materials}

The solutions used for cyclic voltammetry measurements and alloy deposition were prepared by dissolving $\mathrm{RuCl}_{3}$. $\mathrm{H}_{2} \mathrm{O}$ (Acros Organics), $\mathrm{NiCl}_{2} \cdot 6 \mathrm{H}_{2} \mathrm{O}$ (ChemPur) of different concentration proportions, and $\mathrm{NaCl}(\mathrm{POCH})$, which was the complexing agent, in demineralized water. The electrolytes were set to $\mathrm{pH}=1$ by the addition of the concentrated solution of $\mathrm{HCl}$ and $\mathrm{NaOH}(\mathrm{POCH})$, and all experiments were carried out at $25{ }^{\circ} \mathrm{C}$. All reagents were of analytical purity.

Electrochemical experiments were carried out using a Biologic SP potentiostat/galvanostat driven by PC equipped with EC-Lab software. The working electrode was a polycrystalline gold disk electrode of $0.196 \mathrm{~cm}^{2}$ area. The counter-electrode was a platinum coil. The potential was determined with respect to the saturated calomel electrode (SCE). Before each experiment, the gaseous argon was purged to the electrolyte to remove the trace of dissolved oxygen.

Electrodeposition of the Ni-Ru alloys in potentiostatic measurements was carried out on etched copper plates of a $2.8 \mathrm{~cm}^{2}$ area. Electrodes were used immediately after preparation to avoid the oxidation of the copper surface. The oxygen from electrolytes was removed by bubbling $\mathrm{N}_{2}$ into the solution. During plating experiments, the solution was not stirred.

\section{Characterization of the nickel-ruthenium alloys}

The elemental composition of the coatings obtained was determined using the XRF method (Rigaku Rimini) with the Palladium lamp as a source of radiation. The phase composition was analyzed with the XRD method (Rigaku MiniFlex II) with the use of a copper tube $(\lambda=1.54059)$. The diffractograms obtained were compared with characteristics cards from the ICDD base. The SEM images of electrodes after the deposition process were obtained with the use of a scanning microscope (Hitachi Su-70). The surface of alloys was investigated by AFM measurements (Ntegra Aura) with NSG03 tips in semi-contact mode.

\section{Catalytic properties of deposited Ni-Ru coatings}

All the Ni-Ru electrodes were tested in $1 \mathrm{M} \mathrm{L}^{-1} \mathrm{NaOH}$ solution by means of cyclic voltammetry and galvanostatic polarization measurements. Dissolved oxygen from solutions was removed by purging Ar into the solution before each experiment. 


\section{Result and discussion}

\section{Electrochemical studies}

Figure 1 shows the cyclic voltammetry scans obtained for ruthenium electrolytes on gold disk electrodes. According to results published by Mech on the $\mathrm{Ru}^{3+}-\mathrm{Cl}^{-}-\mathrm{H}_{2} \mathrm{O}$, two different cathodic reactions can be observed [47]:

$$
\begin{aligned}
& \mathrm{Ru}^{3+}+3 \mathrm{e}^{-} \rightarrow \mathrm{Ru}^{0} \\
& 2 \mathrm{H}^{+}+2 \mathrm{e} \rightarrow \mathrm{H}_{2}
\end{aligned}
$$

It can be seen that the $\mathrm{Ru}^{3+} / \mathrm{Ru}$ reduction process starts at $0.34 \mathrm{~V}$ (marked on Fig. 1) and it overlaps with reduction of $\mathrm{H}^{+}$ ions (peak A). During the scan, the current density $(j)$ rapidly increases due to the growing number of Ru nuclei deposited on the surface. The highest current density was measured for the lowest potential range $(-1.0$ to $-1.2 \mathrm{~V})$ where the water splitting process can be observed. Black lines are plotted for $\mathrm{Ni}^{2+}$ electrolytes, where the first reduction starts at $-0.55 \mathrm{~V}$ and their maximum (peak B) is observed at $-0.94 \mathrm{~V}$ (Eq. (3)).

$\mathrm{Ni}^{2+}+2 \mathrm{e}^{-} \rightarrow \mathrm{Ni}^{0}$

The anodic peak for the first scan $(-1.0 \mathrm{~V})$ is very weak (maximum at $-0.32 \mathrm{~V}$ ) and belongs to oxidation of the metallic Ni from the Au substrate. For more electronegative potential $(-1.2 \mathrm{~V})$, the reduction process takes place much more intensively. The higher current density $\left(j=0.41 \mathrm{Acm}^{-2}\right)$ registered in this cathodic scan and also the much more intensive anodic peak (peak D) indicating the oxidation of metallic nickel are can be seen.

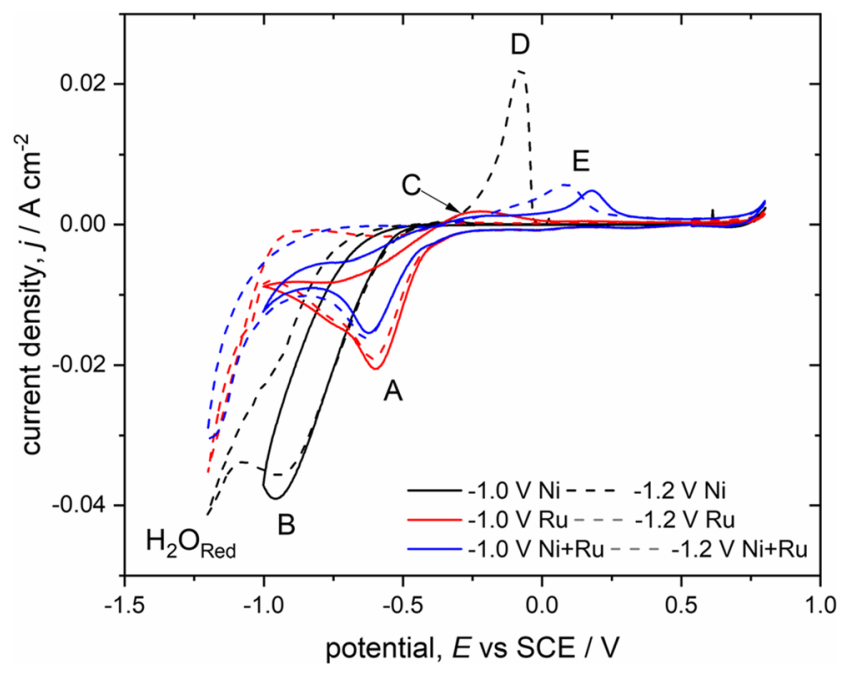

Fig. 1 Cyclic voltammetry registered on Au disk electrode at $40 \mathrm{mVs}^{-1}$ scan rate for electrolytes containing $0.02 \mathrm{M} \mathrm{Ru}^{3+}+0.1 \mathrm{M} \mathrm{Ni}^{2+}$ and mixture of $\mathrm{Ni}-\mathrm{Ru}$ complexes for two different vertex potentials: straight line $-1.0 \mathrm{~V}$ and dashed $-1.2 \mathrm{~V}$
The water decomposition process starts at $-1.16 \mathrm{~V}$. The anodic part of the voltammogram shows the intensive peak D (from -0.32 to $-0.04 \mathrm{~V}$ ) indicating the oxidation of the bulk nickel from the electrode. Anodic signals sweep to $-1.0 \mathrm{~V}$ and $-1.2 \mathrm{~V}$ respectively increase, due to the higher metallic phase obtained in cathodic scans. CV's response to nickel-ruthenium electrolytes is significantly different from the scans of the single metal solutions. The cathodic part connected with peak A region is similar to the only-Ru electrolyte. The dissolution potential, observed in the anodic scan, has been shifted to a more positive value. This observation can be attributed to the formation of a new phase (full-line scan - peak E). Variation of the cathodic scan potentials is increasing the peak intensity, due to higher amount of deposited metal. Contrast between signals from $\mathrm{Ni}$ and quite low $\mathrm{Ni}-\mathrm{Ru}$ response is correlated with the enlarged consumption of electrons in the presence of highly electroactive material in deposit. $\mathrm{Ru}^{3+}$ concentration in the case presented is 5 times lower than $\mathrm{Ni}^{2+}$.

The parameters of Ni-Ru electrodeposition have also been investigated by the linear stripping voltammetry technique (Fig. 2).

$\mathrm{Au}$ electrodes, immersed in $\mathrm{Ru}^{3+}, \mathrm{Ni}^{2+}$, and $\mathrm{Ru}^{3+}{ }_{-} \mathrm{Ni}^{2+}$ electrolytes were polarized by different cathodic potentials for $30 \mathrm{~s}$ and sweep to the anodic region. Anodic scans performed for only-Ru electrolytes do not show any dissolution peak due to the extremely low current efficiency (and mass of $\mathrm{Ru}$ deposit). Measurements for the $\mathrm{Ni}^{2+}$ system show the anodic peak from $-0.7 \mathrm{~V}$, which is located in a potential range (0.30 to $-0.05 \mathrm{~V}$ ). The solution containing nickel and ruthenium precursors presents significantly bigger peaks than were obtained for bulk nickel and located on more positive values (from 0.0 to $0.6 \mathrm{~V}$ ) which indicates the presence of the $\mathrm{Ni}-\mathrm{Ru}$

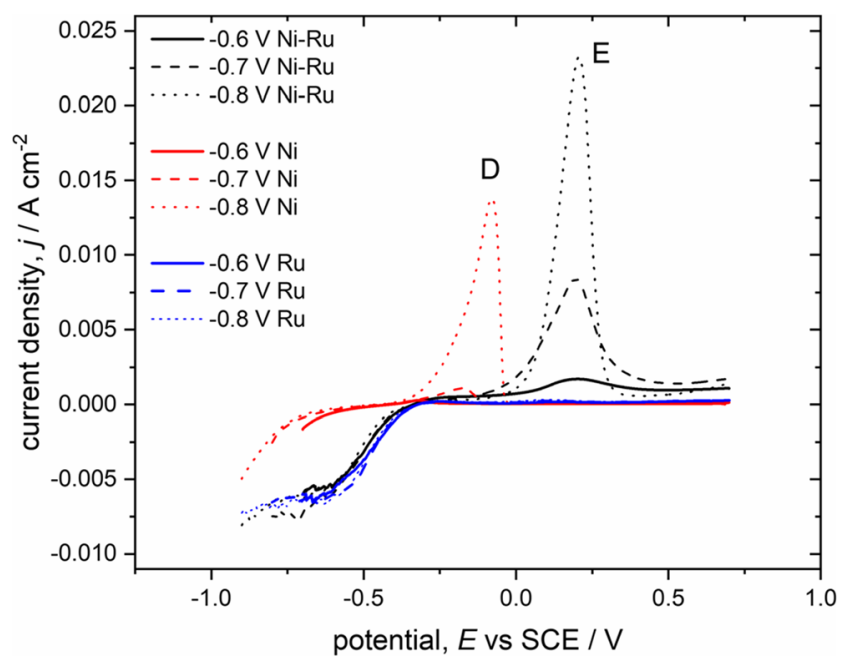

Fig. 2 LSV curves registered on Au disk electrode polarized by different potential values for $30 \mathrm{~s}$ and scanned in anodic direction at $40 \mathrm{mVs}^{-1}$ scan rate. Used electrolytes containing $0.02 \mathrm{M} \mathrm{Ru}^{3+}$ (blue) $0.1 \mathrm{M} \mathrm{Ni}^{2+}$ (red) and mixture of $\mathrm{Ni}-\mathrm{Ru}$ complexes (black) for three different vertex potentials: $-0.6 \mathrm{~V}$ (solid lines), $-0.7 \mathrm{~V}$ (dashed lines), $-0.8 \mathrm{~V}$ (dotted lines) 
phase. The observed differences in anodic peaks intensity between the $\mathrm{Ni}$ and $\mathrm{Ni}$-Ru system can be explained by a stronger hydrogen evolution process during electrode polarization. Discharge of free $\mathrm{H}^{+}$ions and water decomposition increases the $\mathrm{pH}$ value close to the interface. This modification can shift the reduction potentials value for $\mathrm{Ni}^{2+}$ and $\mathrm{Ru}^{3+}$ to more positive and furthermore increase the deposition rate, as what was observed in work connected with the codeposition of Co-Ru coatings from chloride [47-49] and Co-Pd deposits in ammonia electrolytes [50].

\section{Electrodeposition of Ni-Ru alloys on the copper electrode}

Preliminary experiments with Ni-Ru alloy deposition were conducted on Au-sputtered electrodes. However, the vigorous hydrogen evolution process influenced the deposit and led to the formation of non-compact and low-adherent deposits, which cannot be used in further investigation. Considering the very aggressive character of the electrolytes and the presence of ruthenium chloride complexes, the substrate material has to be resistant to the galvanic displacement and corrosion process. Due to these requirements, the copper electrodes have been selected as a suitable substrate for Ni-Ru deposition. Variation of the mass deposition as a function of the deposition potential and electrolyte composition are presented in Fig. 3.

The amount of deposit grows linearly with the application of more negative potentials. The lowest thickness was observed for electrolyte with the smallest $\left(0.1 \mathrm{M} \mathrm{L}^{-1} \mathrm{Ni}^{2+}\right)$ concentration. Opposingly, the highest deposit mass in all experimental series was observed for potential $-1.0 \mathrm{~V}$ and varied from $1.8 \mathrm{mg} \mathrm{cm}^{-2}$ for $0.1 \mathrm{M} \mathrm{L}^{-1} \mathrm{Ni}^{2+}$ to $8.2 \mathrm{mg} \mathrm{cm}^{-2}$ obtained with $1.0 \mathrm{M} \mathrm{L}^{-1} \mathrm{Ni}^{2+}$ in electrolyte.

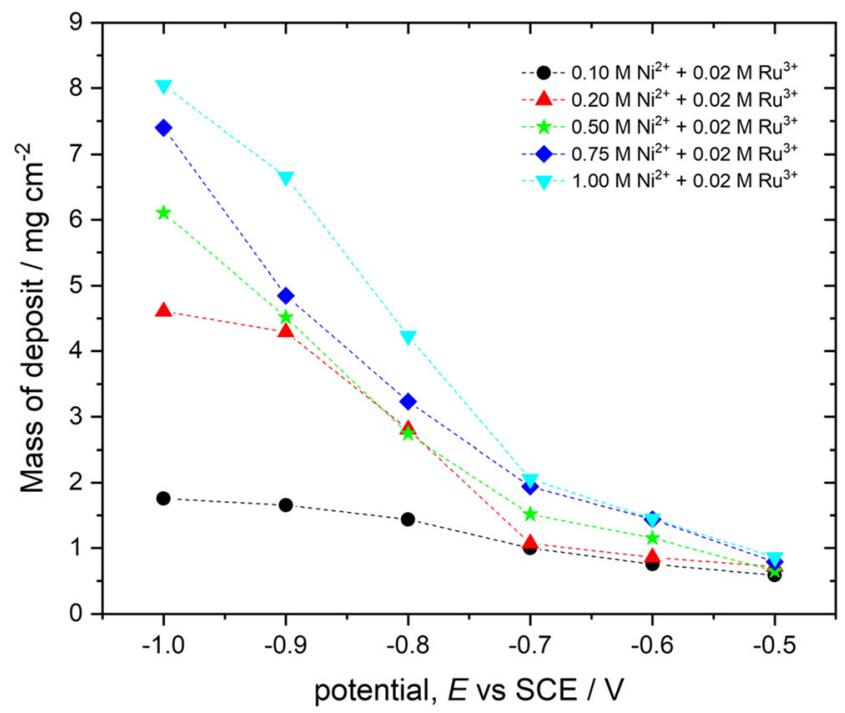

Fig. 3 Mass of obtained coatings electrodeposited from electrolytes containing $0.02 \mathrm{M} \mathrm{Ru}^{3+}$ and various $\mathrm{Ni}^{2+}$ concentration $(0.1-1.0 \mathrm{M}$ $\left.\mathrm{Ni}^{2+}\right)$ and different electrodeposition potentials $(-0.5$ to $-1.0 \mathrm{~V})$
A similar conclusion was observed for the alloy compositions presented in Fig. 4. The lowest nickel content has been registered for a sample electrodeposited from a $-0.5-\mathrm{V}$ and $0.1-\mathrm{M} \mathrm{L}^{-1} \mathrm{Ni}^{2+}$ concentration $(13.5$ mas.\% Ni). The application of the lower electrodeposition potentials for this electrolyte results in the increase of nickel concentration in the alloy to 90.4 mas.\% Ni. Modification of $\mathrm{Ni}-\mathrm{Ru}$ composition can be easily manipulated by variation of their concentrations in electrolyte. Elemental analysis underlined the very interesting fact that nickel can be present in significant amounts in coating even with the application of potential deposition more positive than the reduction of this metal from Ni-only electrolytes. The lowest Ru content in an alloy (6.1 mas.\%) was observed for $-1.0 \mathrm{~V}$ deposition potential for the highest Ni concentration in electrolytes.

\section{Characterization of Ni-Ru alloys}

XRD patterns are presented in Fig. 5. Coatings deposited at $0.5 \mathrm{~V}$ are very thin. Intensive peaks located at $43.49^{\circ}$ and $50.50^{\circ}$ are signals linked with copper substrate respectively (111) and (200) reflexes. From $-0.6 \mathrm{~V}$, it is possible to distinguish small blurred signals from NiRu (100) and (101) phases (ICCD card number: 03-065-6490) along with peaks from the substrate. Application of the more negative potentials gradually shifts the NiRu peak position to the higher value of $2 \theta$ degrees. Nickel incorporation into the hexagonal lattice of $\mathrm{Ru}$ changes the crystallographic structure of the deposit [51]. $\mathrm{NiRu}$ peak intensity also grows with nickel concentration in the alloy. On the other hand, for alloys with a composition between 78 and 86 mas.\% nickel, no peaks associated with $\mathrm{NiRu}$ phases were observed, which is typical for the lack of order in the crystalline structure of the deposit. A

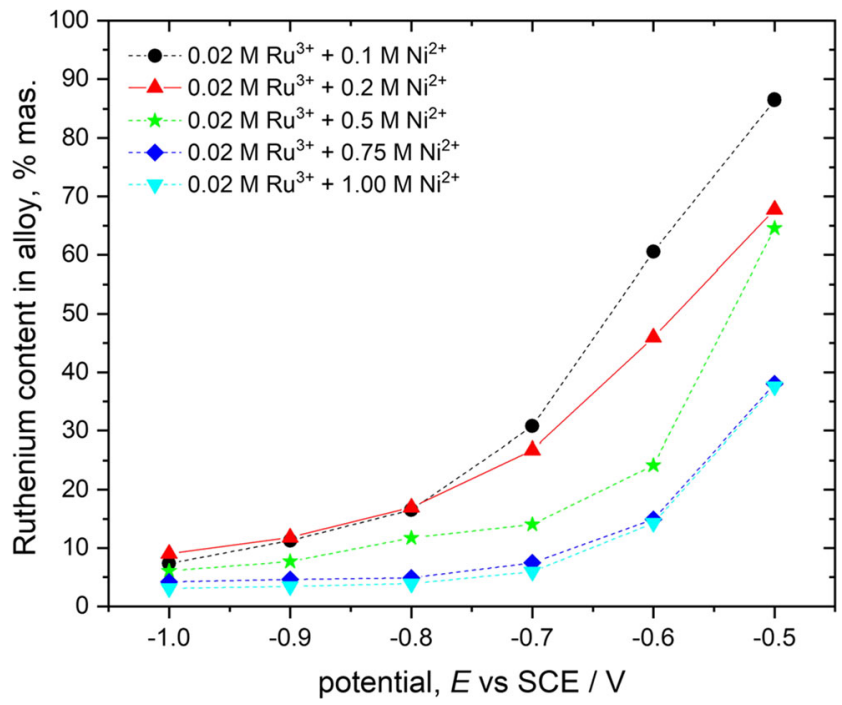

Fig. 4 Composition of Ni-Ru coatings electrodeposited from electrolytes containing $0.02 \mathrm{M} \mathrm{Ru}^{3+}$ and various $\mathrm{Ni}^{2+}$ concentration $\left(0.1-1.0 \mathrm{M} \mathrm{Ni}^{2+}\right)$ and different electrodeposition potentials $(-0.5$ to $-1.0 \mathrm{~V})$ 

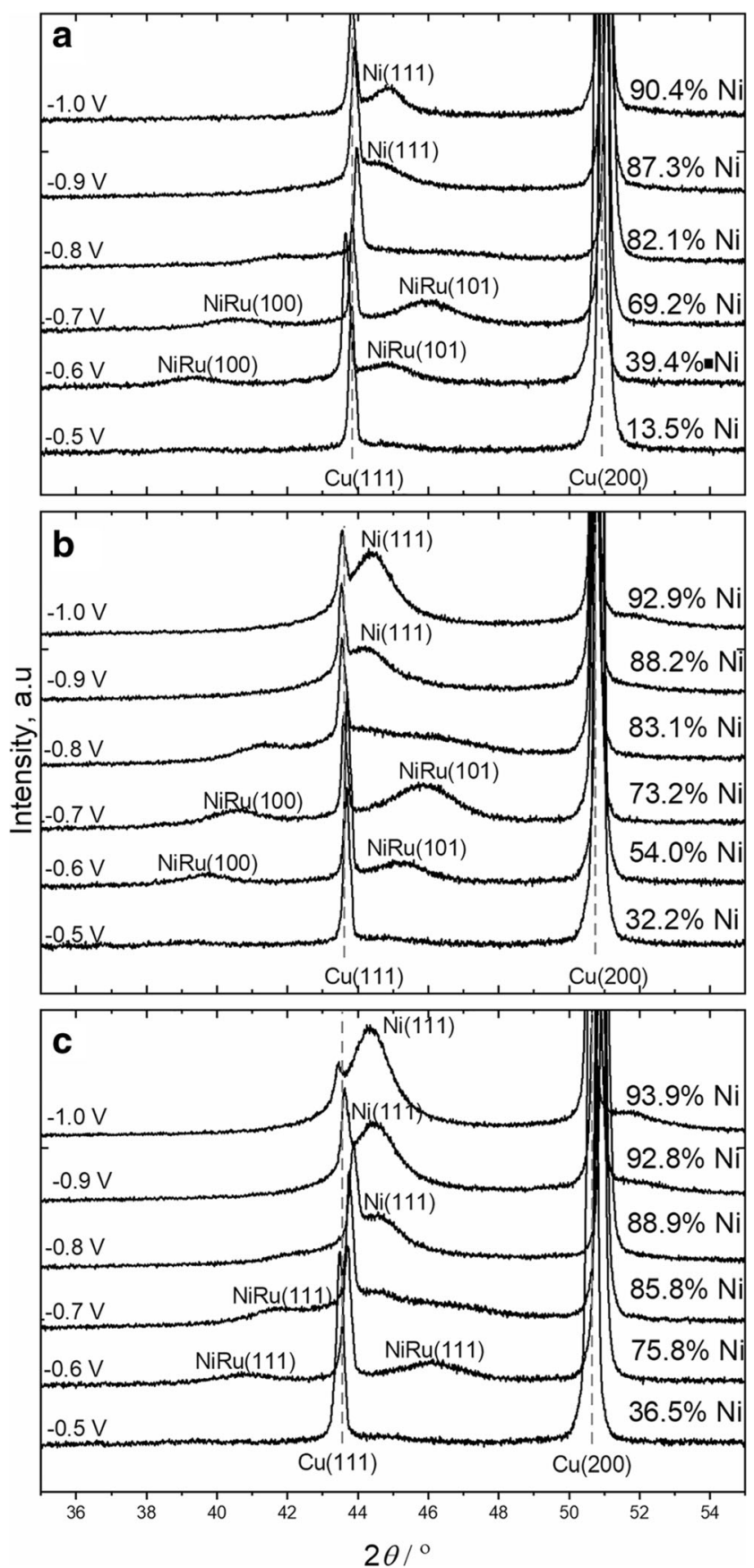

Fig. 5 XRD patterns of $\mathrm{Ni}-\mathrm{Ru}$ coatings electrodeposited from electrolytes containing $0.02 \mathrm{M} \mathrm{Ru}^{3+}$ and various $\mathrm{Ni}^{2+}$ concentration: a $0.1 \mathrm{M}, \mathbf{b} 0.2 \mathrm{M}, \mathbf{c} 1.0 \mathrm{M} \mathrm{Ni}^{2+}$, and different electrodeposition potentials (0.5 to $-1.0 \mathrm{~V}$ )

reorganization of the alloy structure is reported for deposits with higher Ni content, where a new peak from Ni (111) appears. Signals from the metallic Ni phase increase with a higher potential value and nickel concentration in electrolytes.

Visual quality of the deposits obtained for $0.2 \mathrm{M} \mathrm{L}^{-1} \mathrm{Ni}^{2+}$ and $0.02 \mathrm{M} \mathrm{Ru}^{3+}$ and their surface topography examined by AFM have been included in supplementary materials (Table S1 and Table S2 respectively).
Typical SEM images of the Ni-Ru deposits obtained in the different electrolytes and deposition potentials are presented in Table 1. Deposits at -0.5 and $-0.6 \mathrm{~V}$ for all tested electrolytes consist of many small and regular grains. Cracks became visible only in very negative deposition potentials.

\section{Comparative analysis of the catalytic activity of $\mathrm{Ni}-\mathrm{Ru}$ alloys in hydrogen evolution reaction}

The catalytic activity of each electrode was measured using a combination of two different methods: linear voltammetry measurements at $10 \mathrm{mVs}^{-1}$ scan rate (shown on Fig. 6) and controlled galvanostatic experiments in $1 \mathrm{M} \mathrm{L}^{-1} \mathrm{NaOH}$ solution (Fig. S1 in supplementary material).

Representative linear scans for different $\mathrm{Ni}-\mathrm{Ru}$ alloys and copper substrate are shown in Fig. 6. To our best knowledge, this is the first time that electrodeposited $\mathrm{Ni}-\mathrm{Ru}$ alloys have been reported as an HER-active cathodic material. As observed, the blank $\mathrm{Cu}$ substrate shows low catalytic activity in the water splitting process. Structural and morphological differences between alloys obtained with different deposition potentials from $0.02 \mathrm{M} \mathrm{L}^{-1} \mathrm{Ru}^{3+}$ and $0.2 \mathrm{M} \mathrm{L}^{-1} \mathrm{Ni}^{2+}$ electrolytes clearly affect the hydrogen evolution activity. The lowest hydrogen overpotential can be observed for the $\mathrm{Ni}_{93} \mathrm{Ru}_{7}$ alloy. However, taking into consideration the very similar shape and also the low overpotential for the $\mathrm{Ni}_{32} \mathrm{Ru}_{68}$ alloy, with the smallest nickel concentration, high activity cannot only be dependent on the coating composition. Nevertheless, the high surface area and presence of $\mathrm{Ni}-\mathrm{Ru}$ phases can significantly enhance the catalytic activity.

Additionally, the effectiveness of hydrogen evolution reaction was estimated by galvanostatic polarization to reach the current density $(j)=-10 \mathrm{~mA} \mathrm{~cm}^{-2}$. In applied electrochemical conditions, the registered potential value has to be high enough for the decomposition of water molecules. It can clearly be seen that the potential value is going to be stabilize in time (Fig. S1).

Registered potentials from $\mathrm{CP}$ experiments for samples deposited with various potentials and different electrolytes were listed in Fig. 7.

Dashed lines indicate the potential values registered for pure nickel and ruthenium coatings deposited on copper substrates. The lowest potential value for the applied current density $j=-10 \mathrm{~mA} \mathrm{~cm}^{-2}$ was recorded for $\mathrm{Ni}_{93} \mathrm{Ru}_{7}$ alloy $(-1.16$ V). This sample was deposited from the electrolyte $0.2 \mathrm{M} \mathrm{L}^{-1}$ $\mathrm{Ni}^{2+}+0.02 \mathrm{M} \mathrm{L}^{-1} \mathrm{Ru}^{3+}$ at $-1.0 \mathrm{~V}$. This suggests that the small incorporation of $\mathrm{Ru}$ and $\mathrm{Ni}-\mathrm{Ru}$ phases in metallic nickel allows for the enhancement of catalytic activity, which can be directly compared with pure Ru metal. 
Table 1 SEM images of Ni-Ru alloys plated from electrolyte with different $\mathrm{Ni}^{2+}$ concentration and deposition potentials

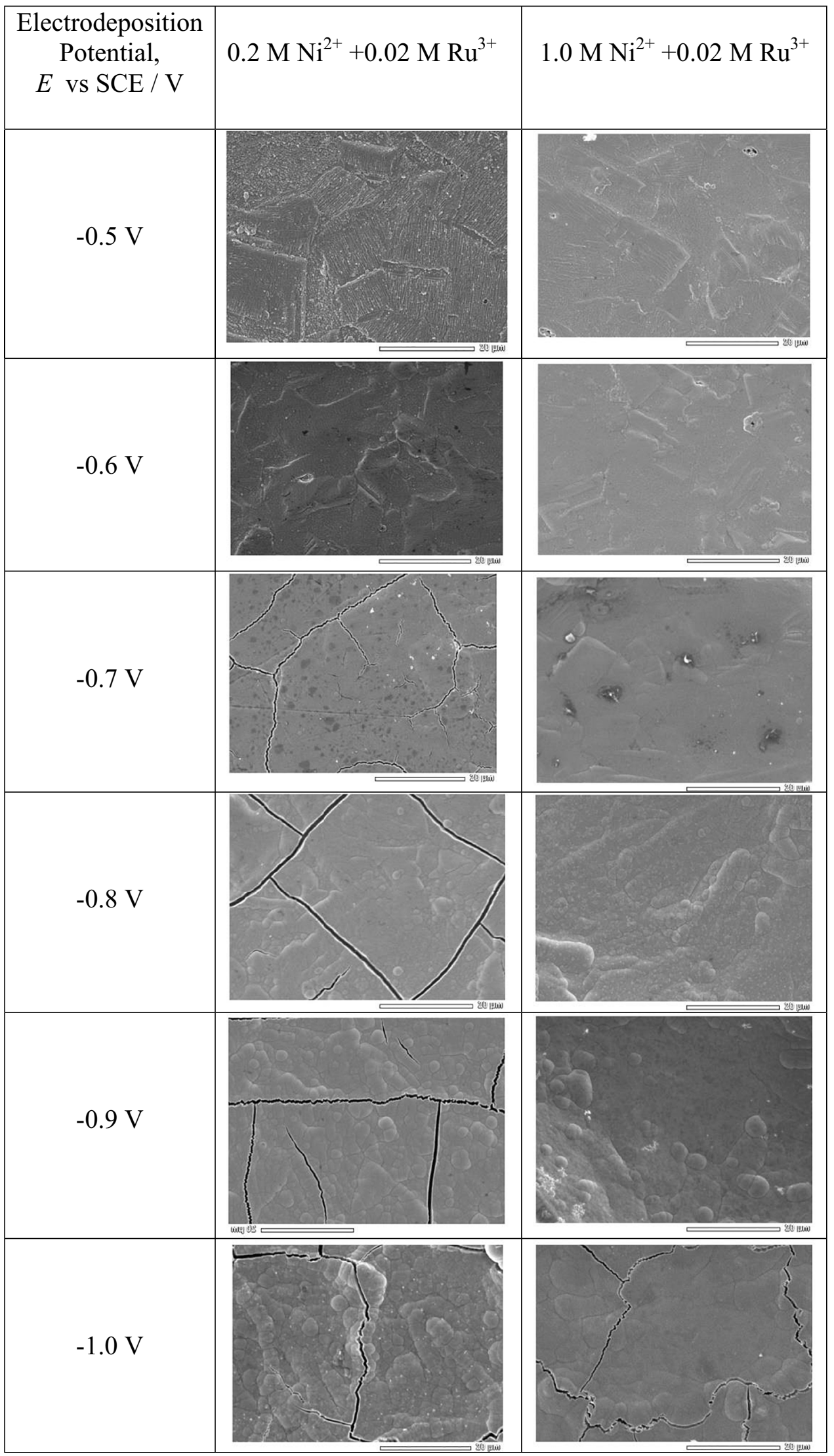




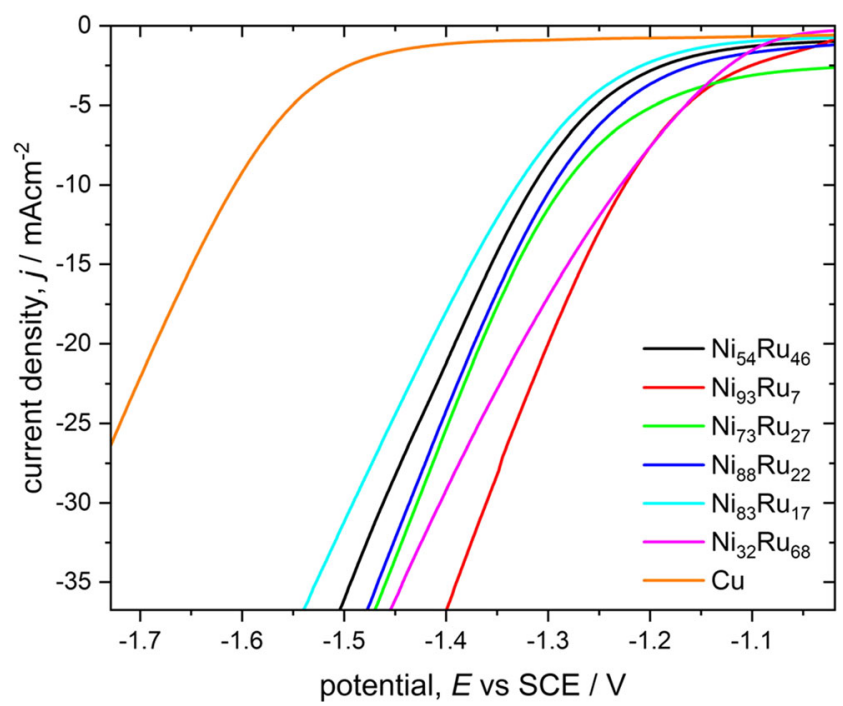

Fig. 6 Polarization curves of $\mathrm{Cu}$ and $\mathrm{Ni}-\mathrm{Ru}$ electrodes obtained from $0.2 \mathrm{M} \mathrm{Ni}^{2+}+0.02 \mathrm{M} \mathrm{Ru}^{3+}$ electrolyte at $10 \mathrm{mVs}^{-1}$ scan rate. All the measurements were performed in $1 \mathrm{M} \mathrm{NaOH}$

\section{Conclusions}

It is possible to obtain nickel and ruthenium alloys by electrochemical deposition from acidic chloride solutions. Cyclic voltammetry showed the presence of a new anodic peak obtained in solutions containing both nickel and ruthenium. The potential value for the anode peak from the alloy phase is more electropositive than for nickel or ruthenium coatings. The rate of NiRu phase growth in the coating is controlled by the rate

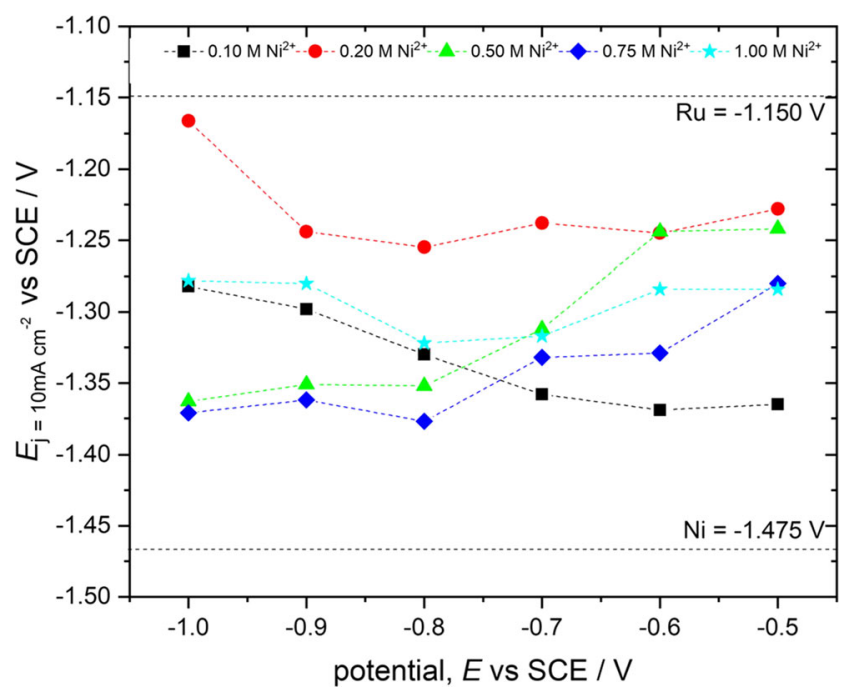

Fig. 7 Potential values extracted from polarization curves (based on Fig. S1) at current density of $-10 \mathrm{~mA} \mathrm{~cm}{ }^{-2}$ performed for different Ni-Ru coatings electrodeposited from electrolytes containing $0.02 \mathrm{M} \mathrm{Ru}^{3+}$ and various $\mathrm{Ni}^{2+}$ concentration $\left(0.1-1.0 \mathrm{M} \mathrm{Ni}^{2+}\right)$ and different electrodeposition potentials $(-0.5$ to $-1.0 \mathrm{~V})$. The reference lines for metallic $\mathrm{Ru}$ and $\mathrm{Ni}$ electrodeposited on copper substrate polarized with of $-10 \mathrm{~mA} \mathrm{~cm}^{-2}$ of $\mathrm{Ru}^{3+}$ ion transport to the electrode surface. Stripping analysis showed that in the $\mathrm{Ni}^{2+}-\mathrm{Ru}^{3+}-\mathrm{Cl}^{-}-\mathrm{H}_{2} \mathrm{O}$ system, nickelruthenium phases are dissolving at more positive potentials than in the case of nickel deposition.

The rate of growth of the coatings can be controlled by the electrolyte composition and the synthesis conditions. Together with the increase of $\mathrm{Ni}^{2+}$ content and the use of more electronegative potentials, an increase in the mass of coatings is observed. The same is with the chemical composition of the obtained alloys, which ranges from 94 mas. $\% \mathrm{Ru}$ at $-0.5 \mathrm{~V}$ and $0.1 \mathrm{M} \mathrm{L}^{-1} \mathrm{Ni}^{2+}+0.02 \mathrm{M} \mathrm{L}^{-1} \mathrm{Ru}^{3+}$ to approx. 4.3 mas.\% $\mathrm{Ru}$ for coatings deposited at $-1.0 \mathrm{~V}$ from electrolytes with 1.0 $\mathrm{M} \mathrm{L}^{-1} \mathrm{Ni}^{2+}$ content.

Phase analysis revealed the presence of $\mathrm{Ni}$-Ru phases in the alloys deposited from -0.6 to $-0.8 \mathrm{~V}$ potentials. The addition of nickel to the ruthenium thin film causes a gradual shift of reflections from the $\mathrm{Ni}-\mathrm{Ru}$ phases towards higher angle values. Exceeding the $\mathrm{Ni}$ content in the coating above 82 mas.\% results in the disappearance of reflections from the $\mathrm{Ni}-\mathrm{Ru}$ alloy phases. Alloys with a content of 87 mas.\% nickel and more show the appearance of reflections from metallic $\mathrm{Ni}$ (111). The coatings obtained are very smooth and shiny for all electrolytes used and deposition potentials. SEM analysis revealed small cracks in alloys obtained from electrolytes with low nickel content ranging from -0.7 to $-1.0 \mathrm{~V}$. The increase of nickel concentration inhibits this process. The coatings are made of tiny, regular grains, creating a compact structure. A small addition of ruthenium to a nickel matrix increases the catalytic activity in the reaction of hydrogen evolution in an alkaline environment. The best electrocatalytic properties are characterized by alloys electrodeposited at the potential of $1.0 \mathrm{~V}$ from electrolyte $0.2 \mathrm{M} \mathrm{L}^{-1} \mathrm{Ni}^{2+}+0.02 \mathrm{M} \mathrm{L}^{-1} \mathrm{Ru}^{3+}$.

Funding information This work was financially supported by the Polish National Center of Science under grant 2016/21/N/ST8/00222.

Open Access This article is distributed under the terms of the Creative Commons Attribution 4.0 International License (http:// creativecommons.org/licenses/by/4.0/), which permits unrestricted use, distribution, and reproduction in any medium, provided you give appropriate credit to the original author(s) and the source, provide a link to the Creative Commons license, and indicate if changes were made.

\section{References}

1. Paidar M, Fateev V, Bouzek K (2009) Membrane electrolysis history, current status and perspective. Electrochim Acta 209:737756

2. Wang M, Wang Z, Gong X, Guo Z (2014) The intensification technologies to water electrolysis for hydrogen production - a review. Renew Sust Energ Rev 29:573-588

3. Rand DA (2011) A journey on the electrochemical road to sustainability. J Solid State Electrochem 15(7-8):1579-1622 
4. Lohrberg K, Kohl P (1984) Preparation and use of Raney-Ni activated cathodes for large scale hydrogen production. Electrochim Acta 29(11):1557-1561

5. De Giz MJ, Machado SAS, Avaca LA et al (1992) High area Ni-Zn and $\mathrm{Ni}-\mathrm{Co}-\mathrm{Zn}$ codeposits as hydrogen electrodes in alkaline solutions. J Appl Electrochem 22(10):973-977

6. Endoh E, Otouma H, Morimoto T et al (1987) New Raney nickel composite-coated electrode for hydrogen evolution. Int J Hydrog Energy 12(7):473-479

7. Herraiz-Cardona I, Ortega E, Vazquez-Gomez L et al (2012) Double-template fabrication of three-dimensional porous nickel electrodes for hydrogen evolution reaction. Int J Hydrog Energy 37(3):2147-2156

8. Jovic BM, Lacnjevac UC, Krstajic NV et al (2013) Ni-Sn coatings as cathodes for hydrogen evolution in alkaline solutions. Electrochim Acta 114:813-818

9. Mauer AE, Kirk DW, Thorpe SJ (2007) The role of iron in the prevention of nickel electrode deactivation in alkaline electrolysis. Electrochim Acta 52(11):3505-3509

10. Han Q, Li X, Chen J, Liu K, Dong X, Wei X (2005) Study of amorphous Ni-S(La) alloy used as HER cathode in alkaline medium. J Alloys Compd 400(1-2):265-269

11. Rosalbino F, Maccio D, Angelini E et al (2005) Electrocatalytic properties of $\mathrm{Fe}-\mathrm{R}(\mathrm{R}=$ rare earth metal) crystalline alloys as hydrogen electrodes in alkaline water electrolysis. J Alloys Compd 403(1-2):275-282

12. Rosalbino F, Maccio D, Angelini E et al (2008) Characterization of Fe-Zn-R ( $\mathrm{R}=$ rare earth metal) crystalline alloys as electrocatalysts for hydrogen evolution. Int J Hydrog Energy 33(11):2660-2667

13. Zheng Z, Li N, Wang C-Q, Li DY, Zhu YM, Wu G (2012) Ni-CeO composite cathode material for hydrogen evolution reaction in alkaline electrolyte. Int J Hydrog Energy 37(19):13921-13932

14. Solmaz R, Doner A, Kardas G (2009) The stability of hydrogen evolution activity and corrosion behavior of $\mathrm{NiCu}$ coatings with long-term electrolysis in alkaline solution. Int J Hydrog Energy 34(5):2089-2094

15. Danaee I, Noori S (2011) Kinetics of the hydrogen evolution reaction on NiMn graphite modified electrode. Int J Hydrog Energy 36(19):12102-12111

16. Choquette Y, Brossard L, Lasia A et al (1990) Study of the kinetics of hydrogen evolution reaction on Raney nickel composite-coated electrode by AC impedance technique. J Electrochem Soc 137(6): 1723-1730

17. Norskov JK, Bligaard T, Logadottir A et al (2005) Trends in the exchange current for hydrogen evolution. J Electrochem Soc 152: 23-26

18. Norskov JK, Bligaard T, Rossmeisl J et al (2009) Towards the computational design of solid catalysts. Nat Chem 1:37-46

19. Quinano P, Juarez F, Santos E et al (2014) Volcano plots in hydrogen electrocatalysis - uses and abuses. Beilstein J Nanotechnol 5: 846-854

20. Greeley J, Norskov JK, Kibler LA et al (2006) Hydrogen evolution over bimetallic systems: understanding the trends. ChemPhysChem 7(5):1032-1035

21. Zabinski PR, Nemoto H, Meguro S et al (2003) Electrodeposited Co-Mo-C cathodes for hydrogen evolution in a hot concentrated $\mathrm{NaOH}$ solution. J Electrochem Soc 150:717-722

22. Zabinski PR, Mech K, Kowalik R (2013) Electrocatalytically active Co-W and Co-W-C alloys electrodeposited in magnetic field. Electrochim Acta 104:542-548

23. Marceta-Kaninski MP, Miulovic SM, Tasic GS et al (2011) A study on the $\mathrm{Co}-\mathrm{W}$ activated $\mathrm{Ni}$ electrodes for the hydrogen production from alkaline water electrolysis - energy saving. Int J Hydrog Energy 36(9):5227-5235
24. Elezovic NR, Jovic VD, Krstajic NV (2005) Kinetics of the hydrogen reaction on Fe-Mo film deposited on mild steel support in alkaline solution. Electroochim Acta 50(28):5594-5601

25. Rosalbino F, MacCi D, Saccone A et al (2011) Fe-Mo-R ( $\mathrm{R}=$ rare earth metal) crystalline alloys as a cathode material for hydrogen evolution reaction in alkaline solution. Int J Hydrog Energy 36(3): 1965-1973

26. Luo B, Ren B, Xu Y et al (2007) A new method to improve surface morphology of Ni-Fe-Mo-Co alloy electrode and its catalytic activity for HER. Rare Metals 26(3):205-212

27. Safizadeh F, Holachi G, Ghali E (2018) Electrocatalytic activity and corrosion behavior of $\mathrm{Fe}-\mathrm{Mo}$ and $\mathrm{Fe}-\mathrm{Mo}-\mathrm{P}$ coatings employed as cathode material for alkaline water electrolysis. Int J Hydrog Energy 43:7938-7945

28. Krstajic NV, Jovic VD, Gajic-Krstajic LJ et al (2008) Electrodeposition of Ni-Mo alloy coatings and their characterization as cathodes for hydrogen evolution in sodium hydroxide solution. J Hydrogen Energy 33(14):3676-3687

29. Tasic GS, Maslovara SP, Zugic DL, Maksic AD, Marceta Kaninski MP (2011) Characterization of the Ni-Mo catalyst formed in situ during hydrogen generation from alkaline water electrolysis. J Hydrogen Energy 36(18):11588-11595

30. Hong SH, Ahn SH, Choi J, Kim JY, Kim HY, Kim HJ, Jang JH, Kim H, Kim SK (2015) High-activity electrodeposited NiW catalysts for hydrogen evolution in alkaline water electrolysis. Appl Surf Sci 349:629-635

31. Ohgai T, Tanaka Y, Washio R (2004) Nanocrystalline structure and soft magnetic properties of nickel-molybdenum alloy thin films electrodeposited from acidic and alkaline aqueous solutions. J Solid State Electrochem 17:743-750

32. Beltowska-Lehman E, Bigos A, Indyka P, Kot M (2012) Electrodeposition and characterization of nanocrystalline Ni-Mo coatings. Surf Coat Technol 211:67-71

33. Maslovara SL, Marceta-Kaninski MP, Perovic IM et al (2013) Novel ternary Ni-Co-Mo based ionic activator for efficient alkaline water electrolysis. J Hydrogen Energy 38:7733-7740

34. Sheng W, Gastier HA, Shao-Horn Y (2010) Hydrogen oxidation and evolution reaction kinetics on platinum: acid vs alkaline electrolytes. J Electrochem Soc 157:1256-1260

35. Yang TH, Pyun SI (1996) An investigation of the hydrogen adsorption reaction into, and the hydrogen evolution reaction from, a Pd foil electrode. J Electroanal Chem 414:127-133

36. Mech K, Boczkal G, Pałka P, Zabiński P, Kowalik R (2014) Synthesis of Co-Pd alloys by co-electroreduction of aquachlorocobalt(II) and palladium(II) complexes. J Solid State Electrochem 18(11):3121-3127

37. Liu H, Li W, Manthiram A (2009) Factors influencing the electrocatalytic activity of Pd 100- x Co x $(0 \leq \mathrm{x} \leq 50)$ nanoalloys for oxygen reduction reaction in fuel cells. Appl Catal, B 90(1-2):184 194

38. Tang J, Zhao X, Zuo Y, Ju P, Tang Y (2015) Electrodeposited PdNi-Mo film as a cathode material for hydrogen evolution reaction. Electrochim Acta 174:1041-1049

39. Krstajic NV, Burojevic S, Vracar LM (2000) Determination of kinetics parameters of the hydrogen evolution on Pd-Ni alloys by ac impedance. J Hydrogen Energy 25(7):635-641

40. Lucentini I, Casanovas A, Llorca J (2019) Catalytic ammonia decomposition for hydrogen production on $\mathrm{Ni}, \mathrm{Ru}$ and $\mathrm{NiRu}$ supported on $\mathrm{CeO}_{2}$. J Hydrogen Energy 25:12693-12707

41. Ding J, Shao Q, Feng Y, Huang X (2018) Ruthenium-nickel sandwiched nanoplates for efficient water splitting electrocatalysis. Nano Energy 47:1-7

42. Wang M, Au CT, Lai SY (2015) H2 production from catalytic steam reforming of n-propanol over ruthenium and rutheniumnickel bimetallic catalysts supported on ceria-alumina oxides with different ceria loadings. Int J Hydrog Energy 40(40):13926-13935 
43. Bianchi I, Guerrini E, Trasatti S (2005) Electrocatalytic activation of $\mathrm{Ni}$ for $\mathrm{H} 2$ evolution by spontaneous deposition of $\mathrm{Ru}$. Chem Phys 319(1-3):192-199

44. Macounová K, Jirkovský J, Makarova MV, Franc J, Krtil P (2009) Oxygen evolution on Ru1 - x Ni x O2-y nanocrystalline electrodes. J Solid State Electrochem 13(6):959-965

45. Gebert A, Lacroix M, Savadogo O, Schulz R (2000) Cathodes for chlorate electrolysis with nanocrystalline $\mathrm{Ti}-\mathrm{Ru}-\mathrm{Fe}-\mathrm{O}$ catalyst. J Appl Electrochem 30(9):1061-1067

46. Blouin M, Roué L, Yip SH et al (1997) Metastable Ti-Ru-Fe-O nanocrystalline alloys for the hydrogen evolution reaction in the chlorate industry. Mater Sci Forum 235-238:979-984

47. Mech K, Mech J, Zsbinski P et al (2015) Electrochemical deposition of alloys in Ru3+-Co2+-Cl-H2O system. J Electroanal Chem 748:76-81
48. Kutyła D, Kołczyk K, Kowalik R et al (2016) Electrochemical deposition of ruthenium and cobalt-ruthenium alloys from acidic chloride ions containing baths. Arch Metall Mater 61:1221-1228

49. Jafari Fesharaki M, Nabiyouni GR, Dégi J, Pogány L, Révész Á, Bakonyi I, Péter L (2012) Anomalous codeposition of cobalt and ruthenium from chloride-sulfate baths. J Solid State Electrochem 16(2):715-722

50. Mech K, Żabiński P, Kowalik R, Tokarski T, Fitzner K (2014) Electrodeposition of Co-Pd alloys from ammonia solutions and their catalytic activity for hydrogen evolution reaction. J Appl Electrochem 44(1):97-103

51. Nash P (1986) The Ni-Ru (Nickel-Ruthenium) system. Bull. Alloy Phase Diagr 7(2):130-133

Publisher's note Springer Nature remains neutral with regard to jurisdictional claims in published maps and institutional affiliations. 